\title{
Decomposition and Attribution Analysis of Runoff Alteration of the Dongting Lake in China
}

\author{
Yuyun Huang, Minghui Yu *, Haoyong Tian and Yujiao Liu
}

State Key Laboratory of Water Resources and Hydropower Engineering Science, Wuhan University, Wuhan 430072, China; yyhuang@whu.edu.cn (Y.H.); hoyoung10@whu.edu.cn (H.T.); 2012301580200@whu.edu.cn (Y.L.)

* Correspondence: mhyu@whu.edu.cn; Tel.: +86-135-4523-7963

Received: 2 September 2020; Accepted: 25 September 2020; Published: 30 September 2020

\begin{abstract}
The runoff process in the Dongting Lake has been influenced by climate change and human activities in recent decades. To manage the Dongting Lake efficiently and exploit water resources properly under the background of water shortage, it is desired to detect the factors of runoff change in the Dongting Lake. Hydro-meteorological data from 1961 to 2019 are analyzed to reveal the climate change and runoff alteration of the Dongting Lake comprehensively. Mutation test is used to detect the change points of runoff depth series, finding that 1984 and 2005 are change points and therefore 1961-1983, 1984-2004, and 2005-2019 are regarded as baseline period (BP), period 1 (P1), and period 2 (P2), respectively. Eight methods are used to quantitatively assess the relative contribution of human activities and climate change on runoff variation. It reveals that climate change especially precipitation change plays the dominant role (climate change makes runoff depth increase 70.14-121.51 mm, human activities make runoff depth decrease 51.98-103.35 mm) in runoff alteration in P1 while human activities play a prime role (account for 88.47-93.17\%) in P2. Human activities such as reservoir construction, water consumption, and land-use (land-cover) change may be the main factors that influence the runoff in the Dongting Lake in P2. According to the sensitivity analysis, runoff in the Dongting Lake is more sensitive to climate change in P2 compared with that in $\mathrm{P} 1$, and no matter in $\mathrm{P} 1$ or $\mathrm{P} 2$, runoff is more sensitive to change in precipitation than the change in potential evapotranspiration. Combined with climate forecast, the results of sensitivity analysis can be used to estimate runoff change caused by climate change in the future.
\end{abstract}

Keywords: climate change; human activities; Dongting Lake; statistic method; Budyko-based method; sensitivity analysis

\section{Introduction}

Runoff, an important source of social water use, has changed in many regions of the world in recent decades [1]. The factors for runoff change can be divided into two groups: climate change and human activities [2-4]. Therefore, a lot of studies have attempted to estimate the effects of climate change and human activities on runoff [5-7]. There are four kinds of methods commonly used to separate the effects of human activities and climate change, namely empirical statistics, elasticity-based method, hydrological modeling, and conceptual model [8,9]. Empirical statistics usually establishes a linear relationship between runoff and precipitation. If there is no influence of human activities on runoff, the relationship between runoff series and precipitation series will not change. The most frequently used empirical statistics methods are the simple linear regression (SLR) method and the double-mass curve (DMC) method $[10,11]$. It requires long-time hydrological and meteorological data. The elasticity-based method was proposed by Schaake [12]. It relays on the climate elasticity coefficients to represent the sensitivity of runoff to variations in meteorological factors, then runoff 
change induced by climate change and human activities can be calculated based on the coefficients. There are five kinds of methods for estimating climate elasticity coefficients [13] and analytical method is one of them. For example, Arora [14] have derived the elasticity of runoff to changes in precipitation and potential evapotranspiration $\left(\varepsilon_{P}\right.$ and $\left.\varepsilon_{E 0}\right)$ based on the Budyko framework [15] and water balance equation, and the methods that calculate the runoff change caused by climate change and human activities based on $\varepsilon_{P}$ and $\varepsilon_{E 0}$ belong to Budyko-based method. It employs a simple but more physically realistic background to investigate the catchment hydrological response to environmental changes [16]. The hydrological modeling method is complex. It requires a large number of parameters and some parameters are difficult to obtain [9]. Soil and Water Assessment Tool (SWAT) is a popular model to deal with this issue $[9,17]$. Geomorphology-based hydrological model (GBHM) and Water and Energy Transfer Process for a Large basin model (WEP-L) are also applied to cope with it [5,18]. The conceptual model is proposed by Tomer and Schilling [2] based on a 25-year, small-watershed experiment in Iowa. Unlike the other three methods, the conceptual model was designed to assess relative, rather than absolute magnitudes of runoff variation induced by climate change and human activities [8]. Ye et al. [19] have applied a conceptual model for distinguishing the relative impacts of climate change and human activities on runoff variation in the Poyang Lake.

The Dongting Lake, located on the south bank of the middle reaches of the Yangtze River is the second largest freshwater lake in China. It plays an important role in many aspects, such as water supply [20], flood storage, conservation of biodiversity, tourism, and aquaculture [21,22]. There have been obvious decreasing trends in the annual water discharge and suspended sediment discharge in the Dongting Lake during recent decades [23]. Therefore, decomposition and attribution analysis of runoff alteration is a prerequisite for sustainable development and utilization of water resources in the Dongting Lake. Numerous studies have shown that climate change and human activities are the main two factors on runoff. On the one hand, human activities have disturbed the hydrological regime of the Dongting Lake with the development of society. For example, there are a lot of dams that have been constructed to satisfy the requirement of irrigation, shipping, electricity, flood control, and drought resistance in recent decades. There are two large hydraulic projects, the Gezhouba Dam (GD) and the Three Gorges Dam (TGD) in the head of the middle Yangtze River, upper reaches of the Dongting Lake, operated in 1980 and 2003, respectively. Some researchers have focused on the impacts of the TGD and the GD on the hydrological regime of the Dongting Lake [24,25]. However, reclamation and some other water conservancy projects except dam construction are also the human activities which may alter runoff. On the other hand, climate change is also a factor that accounts for the dramatic change of the hydrological regime in the Dongting Lake. Global warming has strengthened the water cycle in recent decades, which has changed the spatiotemporal pattern between basin precipitation amounts and water circulation $[5,26]$. To manage the Dongting Lake efficiently and exploit water resources of the lake properly under the background of water shortage, it is meaningful to decompose the contribution of human activities and climate change on runoff change in the Dongting Lake.

Yuan et al. [27] have applied one of the Budyko-based methods to assess the contribution of human activities and climate change to runoff change of three sub-lakes of the Dongting Lake separately. In this study, the whole Dongting Lake is taken as the study area, and more comprehensive meteorological and hydrological data including temperature, actual evapotranspiration, precipitation, potential evapotranspiration, and runoff depth from 1961 to 2019 are analyzed to reveal the variation of climate and runoff on all-sides. The next, eight different methods are used to decompose the relative contribution of human activities and climate change on runoff depth variation, and more reliable results are obtained by comparative analysis on these methods. Then, the influence factors for runoff alteration are analyzed. Finally, the sensitivity of the runoff to changes in climatic variables is analyzed, which can reveal the sensitivity of runoff to precipitation and potential evapotranspiration. This study can be a reference for the research in other regions' runoff alterations affected by human activities and climate change. 


\section{Materials and Methods}

\subsection{Study Area}

The Dongting Lake $\left(28^{\circ} 30^{\prime}-30^{\circ} 20^{\prime} \mathrm{N}, 111^{\circ} 40^{\prime}-113^{\circ} 10^{\prime} \mathrm{E}\right)$, with an area about $2625 \mathrm{~km}^{2}$, is the second-largest freshwater lake of China located in north-eastern Hunan province, and on the south bank of the middle reaches of Yangtze River (Figure 1). It is composed of three sub-lakes, named the Eastern, Western, and Southern Dongting Lakes, respectively. Among them, the Eastern Dongting Lake is the largest one. The river-lake system of the Yangtze River and the Dongting Lake is complex. The water of the Yangtze River pours into the Dongting Lake by the Three Outlets (Songzi, Taiping, and Ouchi) which are natural waterways. Besides, there are four rivers (Xiangjiang, Zishui, Yuanjiang, and Lishui) flow directly into the lake. The water of the Dongting Lake naturally flows into the Yangtze River at Chenglingji. Characterized by the subtropical monsoon climate, the Dongting Lake is hot and rainy in summer, but warm and dry in winter. The annual mean precipitation and temperature in the Dongting Lake are about $1350 \mathrm{~mm}$ and $17.4^{\circ} \mathrm{C}$, respectively. Precipitation in this area exhibits remarkable seasonal variation, the seasonal distribution of discharge in the Dongting Lake is timed simultaneously with precipitation, thus causing frequent flood and drought. The drought has occurred more than 10 times and flood occurred about 8 times in recent decades [28].

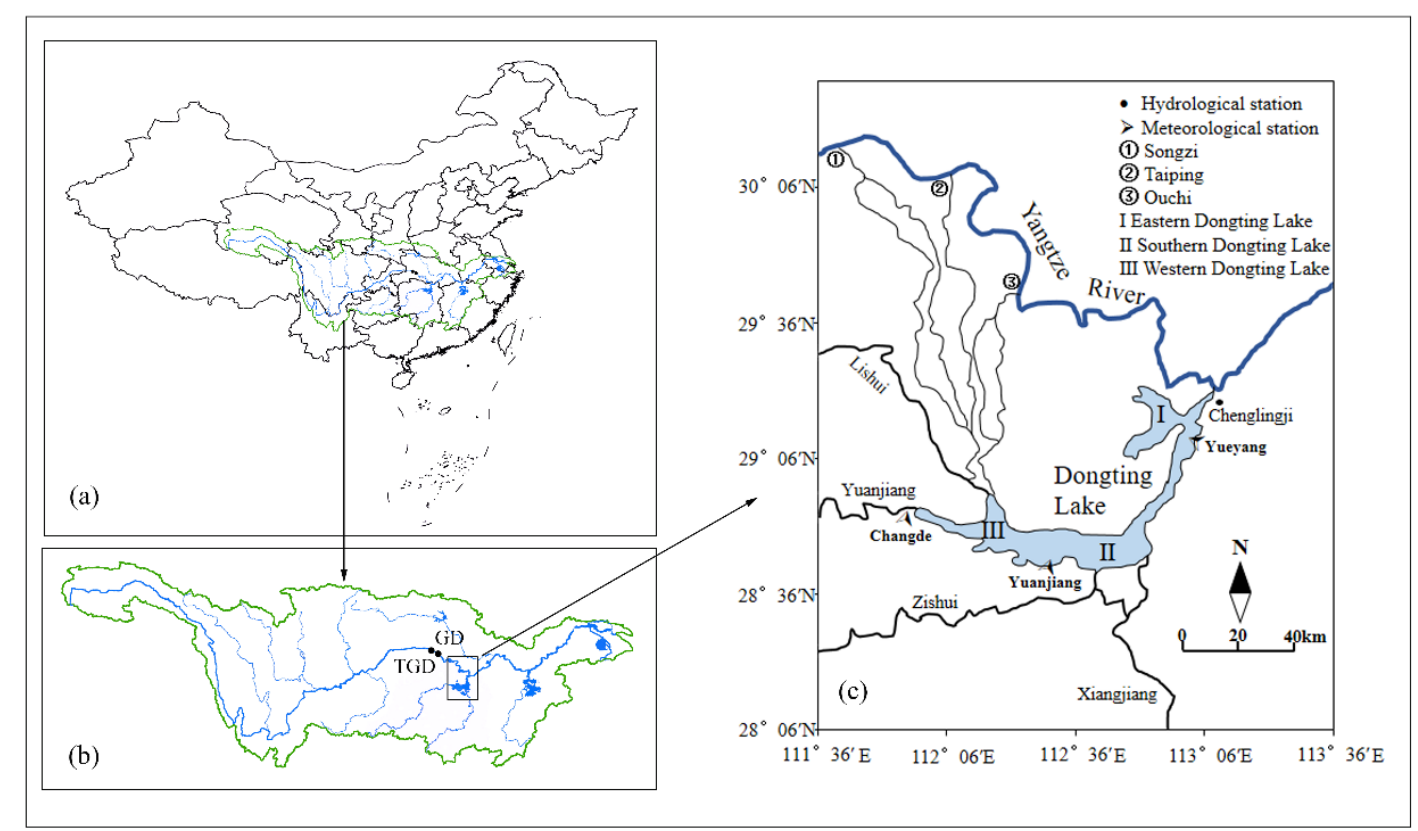

Figure 1. Location of the study region. (a) location of the Yangtze River Basin in China; (b) the Yangtze River Basin: location of the TGD, the GD, and the Dongting Lake; (c) the Dongting Lake: location of the hydrological station and meteorological station.

\subsection{Data Preparation}

Yueyang, Yuanjiang, and Changde meteorological stations are selected as the representative station of the Dongting Lake. Daily meteorological data from 1961-2019 consisted of the temperature, precipitation, actual evapotranspiration, sunshine duration, relative humidity, wind speed, etc. are obtained from the China Meteorological Data Sharing Service System (http://data.cma.cn). The potential evapotranspiration is calculated by the Penman-Monteith equation [29]. The data of the Dongting Lake is calculated by the Tessellation polygon method [30].

\subsection{Methods}

The total change of the runoff depth includes the changes caused by human activities and climate change (Equation (1)). Moreover, the total change of annual mean runoff depth is the difference of the 
annual mean runoff depth of baseline period and variation period (baseline period is the reference, Equation (2). The relative contribution of climate change and human activities in runoff depth variation can be calculated by Equations (3) and (4).

$$
\begin{gathered}
\Delta \bar{Q}_{\text {total }}=\Delta \bar{Q}_{\text {climate }}+\Delta \bar{Q}_{\text {human }} \\
\Delta \bar{Q}_{\text {total }}=\Delta \bar{Q}_{\text {variation }}-\Delta \bar{Q}_{\text {baseline }} \\
\mu_{\text {climate }}=\frac{\Delta \bar{Q}_{\text {climate }}}{\Delta \bar{Q}_{\text {total }}} \times 100 \% \\
\mu_{\text {human }}=\frac{\Delta \bar{Q}_{\text {human }}}{\Delta \bar{Q}_{\text {total }}} \times 100 \%
\end{gathered}
$$

where $\Delta \bar{Q}_{\text {total }}$ is the total change of the annual mean runoff depth (mm); $\Delta \bar{Q}_{\text {variation }}$ is the annual runoff depth during variation period $(\mathrm{mm}) ; \Delta \bar{Q}_{\text {baseline }}$ is the annual runoff depth during the baseline period $(\mathrm{mm}) ; \Delta \bar{Q}_{\text {climate }}$ is the runoff depth change caused by climate change (mm); $\Delta \bar{Q}_{\text {human }}$ is the runoff depth change caused by human activities $(\mathrm{mm}) ; \mu_{\text {climate }}$ and $\mu_{\text {human }}$ is the contribution rate of the climate change and human activities to runoff depth change.

\subsubsection{Simple Linear Regression Method}

Simple linear regression (SLR) is a statistical method that establishes the linear relation between runoff and precipitation, which does not consider the physical processes [31]. The required meteorological data of this method is limited, many researchers have applied SLR to estimate the relative contributions of climate change and human activities to changes in runoff or sediment $[10,31,32]$.

The regression equation between runoff depth and precipitation in the baseline period can be expressed as Equation (5). If there is no human activity, the constants ( $a$ and $b$ ) will not change with time, therefore the reconstructed runoff depth only affected by climate during the variation can be calculated by Equation (6).

$$
\begin{gathered}
Q_{\text {baseline }}=a P_{\text {baseline }}+b \\
Q_{\text {reconstruct }}=a P_{\text {variation }}+b
\end{gathered}
$$

where $a$ and $b$ are constant, determined by runoff depth and precipitation in baseline period; $Q_{b a s e l i n e}$ is annual mean runoff depth in the baseline period $(\mathrm{mm}) ; P_{\text {baseline }}$ is annual mean precipitation in the baseline period (mm); $Q_{\text {reconstruct }}$ is annual mean runoff depth only effected by the climate in the variation period $(\mathrm{mm})$, and $P_{\text {variation }}$ is annual mean precipitation in the variation period $(\mathrm{mm})$.

The runoff depth change caused by human activities and climate change can be estimated by Equations (7) and (8).

$$
\begin{gathered}
\Delta \bar{Q}_{\text {human }}=\bar{Q}_{\text {variation }}-\bar{Q}_{\text {reconstruct }} \\
\Delta \bar{Q}_{\text {climate }}=\Delta \bar{Q}_{\text {total }}-\Delta \bar{Q}_{\text {human }}
\end{gathered}
$$

where $\Delta \bar{Q}_{\text {human }}$ refers to the runoff depth changes caused by human activities during the variation period (mm); $\Delta \bar{Q}_{\text {climate }}$ refers to the runoff depth changes caused by climate change during the variation period (mm); $\bar{Q}_{\text {variation }}$ is the observed annual mean runoff depth during the variation period (mm); $\bar{Q}_{\text {reconstruct }}$ is annual mean runoff depth during variation period only affected by climate change ( $\left.\mathrm{mm}\right)$; the contribute rates of climate change and human activities are calculated by Equations (3) and (4).

\subsubsection{Double-Mass Curve Method}

The double-mass curve (DMC) is a simple, visual, and practical method, and it is highly applied in the consistency test of long-term hydro-meteorological data [11]. Recently, it has been applied to assess the impacts of climate change and human activities to runoff and sediment changes [10,12,32]. 
The DMC is composed of cumulative values of two parameters plotted against one another over a certain time span [33]. The theory of the DMC is based on the fact that a plot of the two cumulative quantities during the same period exhibits a straight line so long as the proportionality between the two remains unchanged [11].

The linear relationship between cumulative runoff depth and cumulative precipitation during the baseline period can be expressed as Equation (9), and the reconstructed cumulative runoff depth in the variation period, which is only affected by climate change, is calculated by Equation (10).

$$
\begin{gathered}
\sum_{i=1}^{t} Q_{i}^{\text {baseline }}=c \sum_{i=1}^{t} P_{i}^{\text {baseline }}+d \\
\sum_{i=1}^{t} Q_{i}^{\text {reconstruct }}=c \sum_{i=1}^{t} P_{i}^{\text {variation }}+d
\end{gathered}
$$

where $c$ and $d$ are constant, which can be calculated by $\sum_{i=1}^{t} Q_{i}^{\text {baseline }}$ and $\sum_{i=1}^{t} P_{i}^{\text {baseline }} ; \sum_{i=1}^{t} P_{i}^{\text {baseline }}$ is the cumulative precipitation in the baseline period $(\mathrm{mm}) ; \sum_{i=1}^{t} P_{i}^{\text {variation }}$ is the cumulative precipitation during the variation period (mm); $\sum_{i=1}^{t} Q_{i}^{\text {baseline }}$ is the cumulative runoff depth in the baseline period (mm); $\sum_{i=1}^{t} Q_{i}^{\text {reconstruct }}$ is the cumulative runoff depth only affected by climate change during the variation period ( $\mathrm{mm}$ ); So the runoff depth changes caused by human activities and climate change can be obtained by Equations (7) and (8), and contribute rate is calculated by Equations (3) and (4).

\subsubsection{Budyko-Based Methods}

Given independent variables of precipitation and potential evapotranspiration which are considered as complete climate-controlled variables, so changes of river runoff due to climate change could be described as [34-36]

$$
\Delta \bar{Q}_{\text {climate }}=\frac{\partial Q}{\partial P} \Delta P+\frac{\partial Q}{\partial E_{0}} \Delta E_{0}
$$

where $Q$ is the runoff depth (mm); $P$ is the precipitation $(\mathrm{mm}) ; E_{0}$ is the potential evapotranspiration $(\mathrm{mm}) ; \Delta Q, \Delta P$, and $\Delta E_{0}$ are the change of runoff depth, precipitation, and potential evapotranspiration, respectively $(\mathrm{mm})$.

The climate elasticity of runoff $(\varepsilon)$ can be defined as the ratio of the runoff variation rate to the variation rate of a certain climate factor [13]:

$$
\varepsilon=\frac{\partial Q / Q}{\partial X / X}
$$

where $X$ represents precipitation or potential evapotranspiration in this paper.

Therefore, Equation (11) can be written as

$$
\Delta \bar{Q}_{\text {climate }}=\left(\varepsilon_{P} \Delta P / P+\varepsilon_{E_{0}} \Delta E_{0} / E_{0}\right) Q
$$

where $\varepsilon_{P}$ and $\varepsilon_{E 0}$ are the runoff elasticity to precipitation and potential evapotranspiration, respectively.

The elasticity coefficients are calculated by the Budyko-based method. According to the Budyko framework [16], the ratio of actual evapotranspiration to precipitation $(E / P$, where $E$ is the actual evapotranspiration $(\mathrm{mm}))$ is a function of the aridity index $\left(\phi=E_{0} / P\right)$, which is expressed as

$$
E / P=F(\phi)
$$


Combined with the water balance equation (Equation (15)), the elasticity coefficients of runoff to precipitation and potential evapotranspiration can be calculated as Equations (16) and (17) [15].

$$
\begin{gathered}
P=E+Q+\Delta S \\
\varepsilon_{P}=1+\frac{\phi F_{(\phi)}^{\prime}}{1-F(\phi)} \\
\varepsilon_{E_{0}}=-\frac{\phi F_{(\phi)}^{\prime}}{1-F(\phi)}
\end{gathered}
$$

where $\Delta S$ is the change in water storage $(\mathrm{mm})$, which is assumed to be 0 over a long time (e.g., five to ten years) $[27,37] . F^{\prime}(\phi)$ is the derived function of $F(\phi)$.

Several pieces of research have proposed different functions to describe $F$. Six popular functions are used in this study (Table 1). The parameters ( $m$ in Fu and $\omega$ in Zhang) represent catchment properties which can influence runoff, and these parameters should be calibrated using the data in the baseline period.

Table 1. Functions for the Budyko hypothesis used in this study.

\begin{tabular}{ccc}
\hline Reference & Function & Parameter \\
\hline Schreiber [38] & $F(\phi)=1-\exp (-\phi)$ & Non \\
Ol'dekop [39] & $F(\phi)=\phi \tanh (1 / \phi)$ & Non \\
Pike [40], Turc [41] & $F(\phi)=1 /\left[1+(1 / \phi)^{2}\right]^{0.5}$ & Non \\
Budyko [42] & $F(\phi)=\{\phi[1-\exp (-\phi)] \tanh (1 / \phi)\}^{0.5}$ & Non \\
Fu [43] & $F(\phi)=1+\phi-\left(1+\phi^{m}\right)^{1 / m}$ & $m$ \\
Zhang [44] & $F(\phi)=[1+\omega \phi] /[1+\omega \phi+1 / \phi]$ & $\omega$ \\
\hline
\end{tabular}

\section{Results}

\subsection{Meteorological Data and Hydrological Data Analysis}

According to the water balance equation (Equation (15)), the runoff depth can be simplified as the difference between precipitation and actual evapotranspiration $[27,28,36]$. The Mann-Kendall (MK) test $[45,46]$ is used to analyze the temporal variation of the runoff depth data and detect the change points of runoff depth series [12]. As presented in Figure 2, the mutations occurred around 1984 and 2005. Hence the period of 1961-2019 is divided into three parts. The period of 1961-1983 is the natural time which is regarded as the baseline period (BP). The period of 1984-2004 is variation period 1 (P1), the period of 2005-2019 is variation period 2 (P2). Annual temperature, actual evapotranspiration, precipitation, potential evapotranspiration, and runoff depth series are shown in Figure 3a. Box plots are used to investigate the characteristics of those data in BP, P1, and P2, which include Q1 (the median of the lower half of the sample), Q2 (median of the sample), Q3 (the median of the upper half of the sample), minimum $(\mathrm{Q} 1-1.5 \times \mathrm{IQR}$, where $\mathrm{IQR}=\mathrm{Q} 3-\mathrm{Q} 1)$, maximum $(\mathrm{Q} 3+1.5 \times \mathrm{IQR})$ and outliers (lower than minimum or higher than maximum) (Figure $3 b$ ). In addition, the $\mathrm{Cv}$ (Coefficient of variation) of these variables are calculated (Table 2). 
Table 2. The coefficient of variation of temperature, actual evapotranspiration, precipitation, potential evapotranspiration, and runoff depth.

\begin{tabular}{cccccc}
\hline & \multicolumn{5}{c}{$\mathbf{C v}(\%)$} \\
& $\boldsymbol{T}$ & $\boldsymbol{E}$ & $\boldsymbol{P}$ & $\boldsymbol{E}_{\boldsymbol{0}}$ & $\boldsymbol{Q}$ \\
\hline BP & 2.16 & 10.01 & 19.37 & 4.97 & 52.16 \\
$\mathbf{P 1}$ & 2.77 & 9.11 & 19.20 & 5.44 & 50.62 \\
$\mathbf{P 2}$ & 2.42 & 7.83 & 19.95 & 6.93 & 66.05 \\
\hline
\end{tabular}

Note: $T=$ temperature; $E=$ actual evapotranspiration; $P=$ precipitation; $E_{0}=$ potential evapotranspiration; $Q=$ runoff depth .

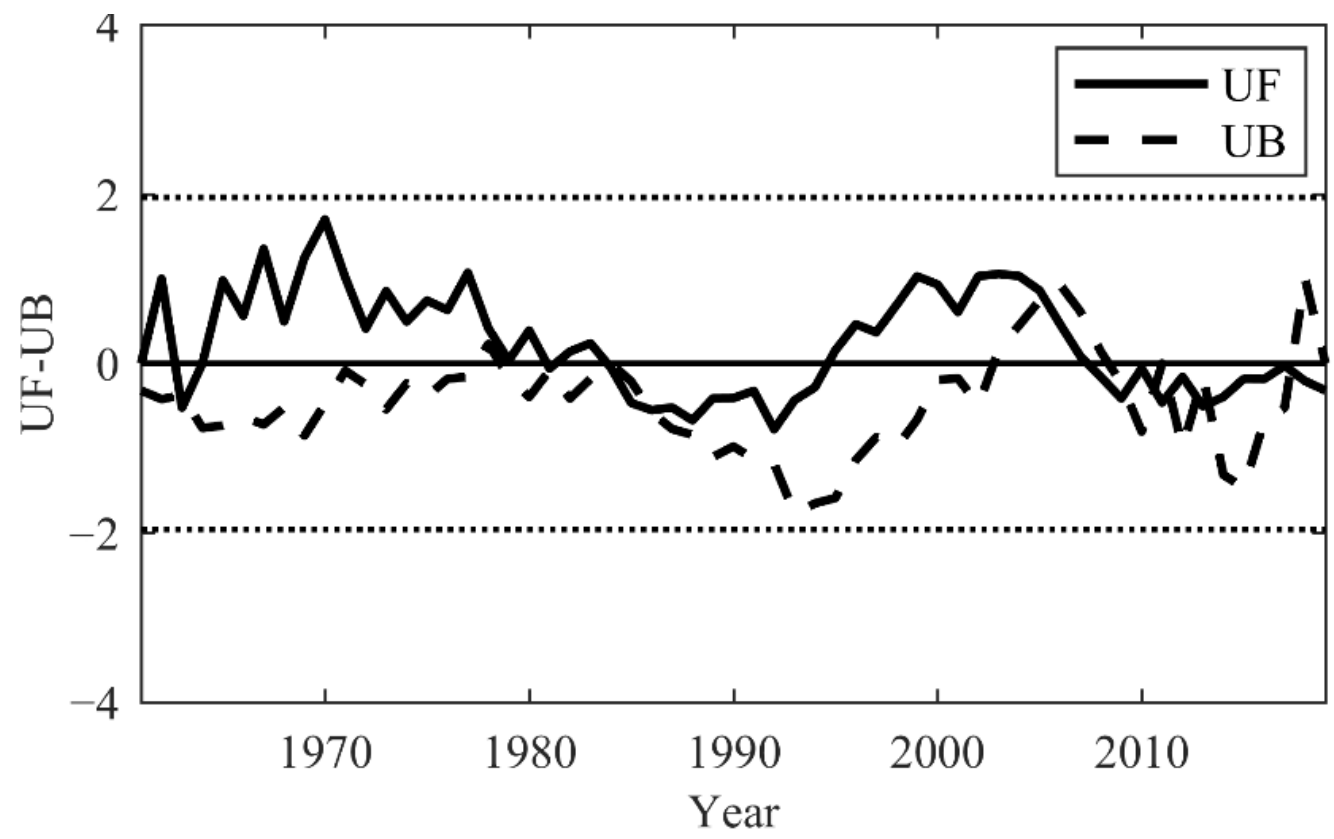

Figure 2. Mutation test result. For the given time series, the Mann-Kendall (MK) test defines the values of test statistic UF as a standardized variable with zero mean and unit standard deviation, and the values of UB are computed backward. The intersection points of the UF and UB curves indicate the possible turning year in the time series at the corresponding threshold level (i.e., \pm 1.96 for $95 \%$ significance level).
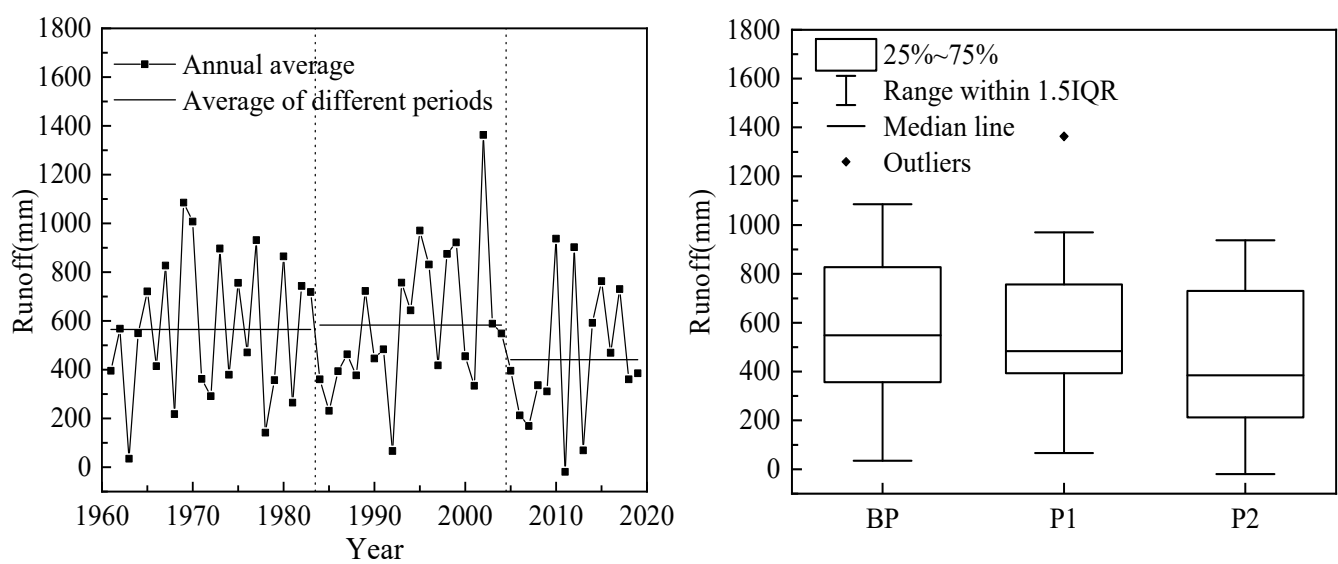

Figure 3. Cont. 

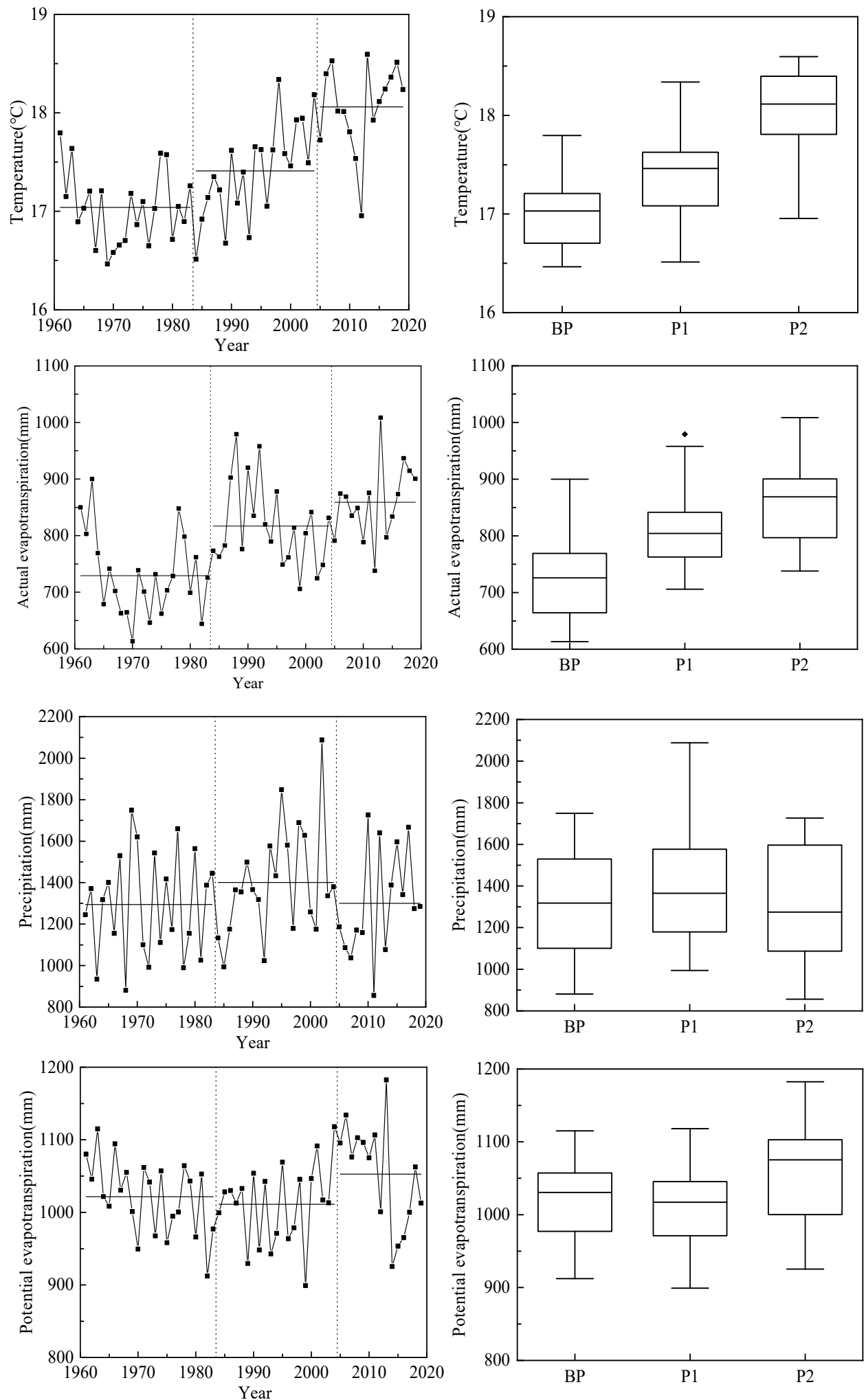

(a)

(b)

Figure 3. (a) Annual temperature, actual evapotranspiration, precipitation, potential evapotranspiration, and runoff depth series; (b) Box plot of annual temperature, actual evapotranspiration, precipitation, potential evapotranspiration, and runoff depth in BP, P1, and P2.

As shown in Figure 3, the average runoff depth in BP is $565.14 \mathrm{~mm}$. The average runoff depth in P1 is $583.30 \mathrm{~mm}$, which is $18.17 \mathrm{~mm}$ higher than that in BP. The average runoff depth in P2 is $440.84 \mathrm{~mm}$, 
which is $124.30 \mathrm{~mm}$ less than that in BP. The runoff depth increased by $3.21 \%$ in P1 and decreased by $22.00 \%$ in P2 compared with BP. The Cv of runoff depth in P2 is larger than other periods, which means the inter-annual change of runoff depth in P2 is greater (Table 2).

Different from runoff depth, the annual temperature is on the rise as a whole (Figure 3a). In the background of global warming, which began in the 1970s [47], the temperature of the Dongting Lake began to increase slowly in the 1970s and rose rapidly from 1997. The average temperature in BP is $17.04{ }^{\circ} \mathrm{C}$. The average temperature in $\mathrm{P} 1$ is $17.41^{\circ} \mathrm{C}$, which is $0.37^{\circ} \mathrm{C}$. higher than that in $\mathrm{BP}$. The average temperature in $\mathrm{P} 2$ is $18.06^{\circ} \mathrm{C}$, which is $1.02{ }^{\circ} \mathrm{C}$. higher than that in $\mathrm{BP}$. It increased by $2.17 \%$ and $6.03 \%$ in P1 and P2 compared with BP, respectively. The temperature in BP is distributed mainly in the low-temperature zone, and that in P2 is distributed mainly in the high-temperature zone (Figure $3 b$ ). The inter-annual change of temperature in P1 is greater than the other two periods (Table 2).

Similar to temperature, there are distinct stepwise increases in actual evapotranspiration over the three periods. The average actual evapotranspiration in BP is $729.36 \mathrm{~mm}$, and that in $\mathrm{P} 1$ and P2 are $817.06 \mathrm{~mm}$ and $859.00 \mathrm{~mm}$, which are $87.70 \mathrm{~mm}$ and $129.64 \mathrm{~mm}$ more than that in BP, respectively. The actual evapotranspiration increased by $12.02 \%$ and $17.78 \%$ in $\mathrm{P} 1$ and $\mathrm{P} 2$ compared with BP, respectively (Figure 3a). However different from temperature, the actual evapotranspiration distributed mainly in low actual evapotranspiration in all three periods (Figure 3b), and the data in P2 distributed most concentrated, which means the inter-annual change in P2 is smaller than BP and P1 (Table 2).

The average precipitation in BP is $1294.50 \mathrm{~mm}$. The average precipitation in P1 is $1400.37 \mathrm{~mm}$, which is $105.87 \mathrm{~mm}$ more than that in $\mathrm{BP}$, and the average precipitation in P2 is $1299.84 \mathrm{~mm}$, which is $5.34 \mathrm{~mm}$ higher than that in BP. It increased by $8.18 \%$ and $0.41 \%$ in P1 and P2, respectively (Figure 3a). The inter-annual change of precipitation in P2 is greater than the other two periods (Table 2), and the data in P2 distributed mainly in a low rainfall zone (Figure $3 b$ ).

The average potential evapotranspiration in BP is $1021.77 \mathrm{~mm}$. The average potential evapotranspiration in P1 is $1011.20 \mathrm{~mm}$, which is $10.57 \mathrm{~mm}$ less than that in BP. The average potential evapotranspiration in P2 is $1052.71 \mathrm{~mm}$, which is $30.94 \mathrm{~mm}$ more than that in BP. It decreased by $1.03 \%$ at first and then increased by $3.03 \%$ (Figure $3 a$ ). Therefore, the evaporation capacity of the Dongting Lake reduced in P1 and improved in P2 compared with BP. The inter-annual change of potential evapotranspiration in BP is the greatest in three periods (Table 2). Located in the humid area, the aridity index $(\phi)$ of the Dongting Lake is less than 1 in all periods, the energy supply limits actual evapotranspiration [17].

\subsection{Assessing Contribution of Climate Change and Human Activity to Runoff Alteration}

Runoff depth alterations caused by climate change and human activities, calculated with eight methods, as well as the relative contribution rates of human activities and climate change to runoff depth change in P1 and P2 are shown in Table 3.

Table 3. Runoff depth alteration caused by climate change and human activities, calculated with eight methods.

\begin{tabular}{|c|c|c|c|c|c|c|c|c|c|}
\hline & & \multicolumn{4}{|c|}{ P1 } & \multicolumn{4}{|c|}{ P2 } \\
\hline & & $\underset{(\mathrm{mm})}{\Delta \bar{Q}_{\text {climate }}}$ & $\begin{array}{c}\Delta \bar{Q}_{\text {human }} \\
(\mathrm{mm})\end{array}$ & $\begin{array}{l}\mu_{\text {climate }} \\
\quad(\%)\end{array}$ & $\begin{array}{l}\mu_{\text {human }} \\
(\%)\end{array}$ & $\begin{array}{c}\Delta Q_{\text {climate }} \\
(\mathrm{mm})\end{array}$ & $\begin{array}{c}\Delta \bar{Q}_{\text {human }} \\
(\mathrm{mm})\end{array}$ & $\mu_{\text {climate }}$ & $\begin{array}{c}\mu_{\text {human }} \\
(\%)\end{array}$ \\
\hline \multirow{2}{*}{$\begin{array}{l}\text { The first group } \\
\text { of methods }\end{array}$} & SLR & 121.51 & -103.35 & 668.88 & -568.88 & 6.12 & -130.42 & -4.92 & 104.92 \\
\hline & DMC & 70.14 & -51.98 & 386.11 & -286.11 & 22.91 & -147.21 & -18.43 & 118.43 \\
\hline \multirow{4}{*}{$\begin{array}{l}\text { The second group } \\
\text { of methods }\end{array}$} & Schereiber & 83.81 & -65.65 & 461.36 & -361.36 & -8.49 & -115.81 & 6.83 & 93.17 \\
\hline & Pike & 94.59 & -76.42 & 520.67 & -420.67 & -11.36 & -112.95 & 9.14 & 90.86 \\
\hline & $\mathbf{F u}$ & 96.01 & -77.84 & 528.48 & -428.48 & -11.55 & -112.75 & 9.29 & 90.71 \\
\hline & Zhang & 88.33 & -70.16 & 486.21 & -386.21 & -9.59 & -114.71 & 7.72 & 92.28 \\
\hline
\end{tabular}


The first group of methods we used is the statistic method including the SLR and the DMC. Both the results of two methods suggest that climate change and human activities have opposite effects on runoff depth change in P1. Climate change causes the runoff depth to increase 70.14-121.51 mm, while human activities make it decrease $51.98-103.35 \mathrm{~mm}$. Thus, the effect of climate change on runoff depth change is greater than that of human activities. As for P2, both the results of two methods indicate that climate change and human activities have opposite effects on runoff depth change. Climate change causes the runoff depth to increase $6.12-22.91 \mathrm{~mm}$, while human activities make it decrease 130.42-147.21 mm. Different from P1, the effect of human activities on runoff depth change is greater than that of climate change. The change of runoff depth is dominated by human activities, while climate change plays a complementary role.

The second group of methods are Budyko-based methods. Different studies propose different methods based on the climate elastic model; six calculation formulations are chosen in this study. Calibrated with the data in BP, $m=2.5$ and $\omega=1.1$. As shown in Table 3, these methods indicate that climate change and human activities influence the runoff depth oppositely in P1. The increase of the runoff depth caused by climate change ranges from $83.81 \mathrm{~mm}$ to $105.81 \mathrm{~mm}$, the decrease of the runoff depth caused by human activities ranges from $65.65 \mathrm{~mm}$ to $87.64 \mathrm{~mm}$. The effect of climate change on runoff depth change is greater than that of human activities. As for P2, these six methods have the same results that both climate change and human activities make runoff depth decrease and human activities play the dominant role. The decrease caused by climate change ranges from $8.49 \mathrm{~mm}$ to $14.34 \mathrm{~mm}$, accounting for $6.83 \%$ to $11.53 \%$ of total runoff depth decrease. The decrease caused by human activities ranges from $109.96 \mathrm{~mm}$ to $115.81 \mathrm{~mm}$, accounting for $88.47-93.17 \%$ of total runoff depth decrease. So human activities play a dominant role in runoff depth alteration, while climate change plays a complementary role in P2.

Generally, for P1, all of these methods show that climate change has the opposite effect on human activities on runoff depth change. Climate change causes runoff depth increase while human activities make it decreased. The decline of runoff depth caused by human activities ranges from $51.98 \mathrm{~mm}$ to $103.35 \mathrm{~mm}$ (average $75.94 \mathrm{~mm}$ ), the increase of runoff depth caused by climate change ranges from $70.14 \mathrm{~mm}$ to $121.51 \mathrm{~mm}$ (average $94.11 \mathrm{~mm}$ ). Climate change plays a dominant role and leads to an increase in runoff depth. As for P2, all of these methods reveal the human activities play a chief part in reducing runoff depth. However, two groups of methods come to the opposite conclusion in the influence of climate change in runoff depth, the SLR and DMC indicate that climate change leads to the runoff depth increasing while the Budyko-based methods show that climate change leads to the runoff depth decrease. As to the SLR and DMC, they consider precipitation as the only climatic factor influences runoff. While the Budyko-based method considered both precipitation and potential evapotranspiration as climatic factors. Hence, in this study, the Budyko-based methods are considered more reliable in partitioning the impact of climate change and human activities on runoff. Based on the second group of methods, the decline of runoff depth caused by human activities accounts for $88.47-93.17 \%$ (average $91 \%$ ), which is the primary reason for runoff depth variation. The SLR and MDC's performances in quantifying the impact of human activities and climate change on runoff alteration are different from region to region [9,31], so both study areas and data should be considered when choosing a method for assessing the effect of climate change and human activities on runoff change.

\section{Discussion}

\subsection{Influence Factors for Runoff}

For P1, climate change makes runoff depth increase while human activities make it decrease, and the runoff depth increased on the whole. The precipitation has increased in P1, which is a completely climatic factor. Actual evapotranspiration also increased in P1, which may be affected by climate change and human activities. However, the effect of increased rainfall is greater. Therefore, precipitation is 
the main factor that influences the runoff in P1. For P2, both climate change and human activities decrease runoff. The precipitation in P2 increases very slightly, and temperature raise causes actual evapotranspiration increase. The influence of temperature might greater than precipitation, so climate change causes runoff decrease as a whole. At the same time, human activities bring about a runoff decrease. Human activities that change the runoff can be divided into two groups: (1) direct impact such as the construction of reservoirs and water consumption; and (2) indirect impacts such as the activities which may change the land-use or land-cover and thereby change the conditions for runoff generation [48]. Firstly, as presented in Figure 4 [49], the midsize reservoirs whose capacity is between 10 and 100 million $\mathrm{m}^{3}$ in Hunan province increased greatly in 2005 (up to 276) and 2017 (up to 362), and the water storage of these reservoirs increased to 3.808 billion $\mathrm{m}^{3}$ in 2018 . The large reservoirs whose capacity is more than 100 million $\mathrm{m}^{3}$ increased gradually from 2001 to 2016 and increased greatly in 2018 (up to 45), and the water storage of large reservoirs increased to 20.388 billion $\mathrm{m}^{3}$ in 2018. Water consumption has also increased in P2 (Figure 5) $[49,50]$. Secondly, land-use or land-cover around the Dongting Lake have changed during 1993-2010: percent coverage of mudflat and meadow decreased, wood coverage rate increased, while the coverage of reed changed little [51]. Although there is little data before 1993, the data mentioned above partly indicated the change of land-use types. Hence land-use or land-cover change may account for the runoff alteration caused by human activities. Besides, the GD and TGD are in the main stream of the Yangtze River upper reaches of the Dongting Lake. However, the mechanisms for these human activities to change the runoff of the lake and how much they each change the runoff still need further research. The underground water also should be considered in further research.

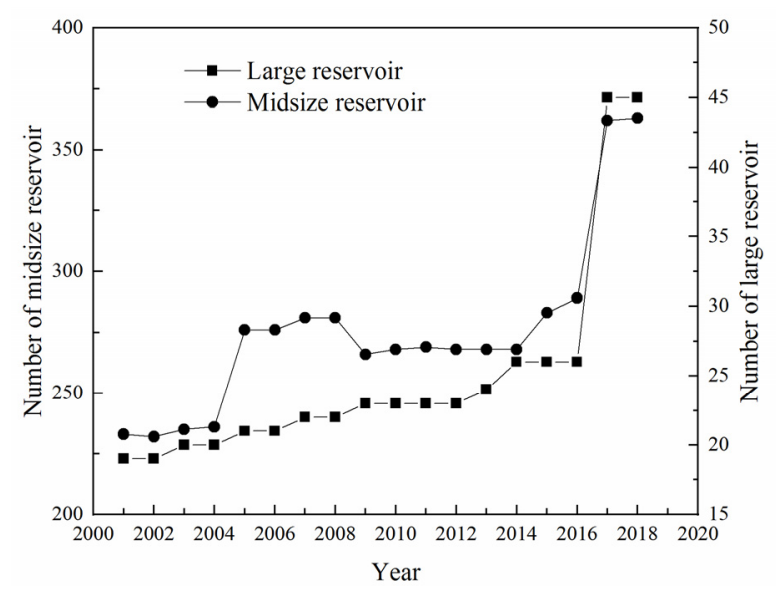

Figure 4. Statistics on the number of midsize and large reservoirs in Hunan province.

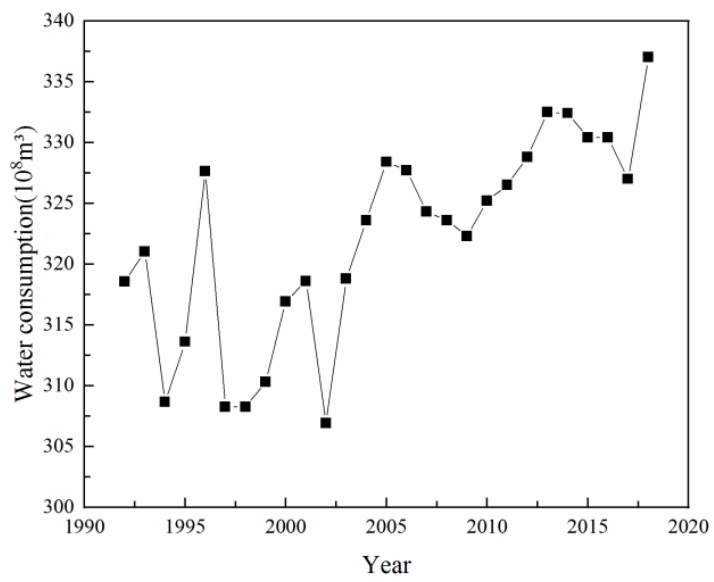

Figure 5. Annual water consumption of Hunan province. 
Generally, climate change plays a dominant role in changing runoff during 1984-2004, and human activities play a chief part in altering runoff during 2005-2019 in the Dongting Lake. Wu et al. suggested that changes in climate played a dominant role in the declining runoff in the Yanhe River during 1997-2011 [7]. Yanhe River, a first-order tributary of the Yellow River, belongs to a semi-arid area in China, while the Dongting Lake belongs to the humid area. Although the study period of the Yanhe River is not the same with this paper, the conclusions of these two studies might concur with the regularity found in the study of Li et al. [36] which indicated that influences of human activities were found considerable in the grassland covered semi-humid area, while climate change functioned remarkably in the semi-arid area with sparse vegetation.

\subsection{Sensitivity Analysis}

As shown in Equation (13), the change in runoff caused by climate change is a function of change in precipitation and change in potential evapotranspiration. In Budyko-based methods, $\varepsilon_{P}$ and $\varepsilon_{E 0}$ in that function can be regarded as sensitivity coefficients. Therefore, the sensitivity coefficients of the two periods are calculated with six formulations in Table 1 , the results are shown in Table 4. In P1, $\varepsilon_{P}$ ranges from 1.76 to 2.19 (average 1.95), which means $1 \%$ change in precipitation results in $1.76 \%$ to $2.19 \%$ (average $1.95 \%$ ) change in runoff; $\varepsilon_{E 0}$ ranges from -1.19 to -0.76 (average -0.95 ), which means $1 \%$ increase in precipitation results in $0.76 \%$ to $1.19 \%$ (average $-0.95 \%$ ) decrease in runoff. While in $\mathrm{P} 2$, $\varepsilon_{P}$ ranges from 1.80 to 2.24 (average 1.99 ), which means $1 \%$ change in precipitation results in $1.80 \%$ to $2.24 \%$ (average $1.99 \%$ ) change in runoff; $\varepsilon_{E 0}$ ranges from -1.24 to -0.80 (average -0.99 ), which means $1 \%$ increase in precipitation results in $0.80 \%$ to $1.24 \%$ (average $-0.99 \%$ ) decrease in runoff.

Table 4. Precipitation elasticity for runoff and potential elasticity for runoff.

\begin{tabular}{ccccc}
\hline & \multicolumn{2}{c}{ P1 } & \multicolumn{2}{c}{ P2 } \\
\hline & $\varepsilon_{P}$ & $\varepsilon_{E_{0}}$ & $\varepsilon_{\boldsymbol{P}}$ & $\varepsilon_{E_{0}}$ \\
\hline Schereiber & 1.76 & -0.76 & 1.80 & -0.80 \\
OL'dekop & 2.19 & -1.19 & 2.24 & -1.24 \\
Budyko & 1.93 & -0.93 & 1.97 & -0.97 \\
Pike & 1.97 & -0.97 & 2.01 & -1.01 \\
Fu & 1.99 & -0.99 & 2.03 & -1.03 \\
Zhang & 1.84 & -0.84 & 1.88 & -0.88 \\
Average & 1.95 & -0.95 & 1.99 & -0.99 \\
\hline
\end{tabular}

Although the values of the climate elasticity calculated by various methods are different, all climate elasticity in P2 is larger than that in P1, which reveals runoff are more sensitive to climate change in P2 compared with $\mathrm{P} 1$. Besides, no matter in $\mathrm{P} 1$ or $\mathrm{P} 2$, runoff is more sensitive to change in precipitation than the change in potential evapotranspiration. In other words, the effect of precipitation to runoff is greater than the evaporation capacity. The average sensitivity coefficients in two periods are used to draw contours with which runoff change can be calculated when there is any change in precipitation or potential evapotranspiration (Figure 6). There is a slight difference between the two periods. With Figure $6 b$, the change of runoff in the future can be rough estimated when the change of precipitation and potential evapotranspiration is known. Moreover, $\varepsilon_{P}$ and $\varepsilon_{E 0}$ in the Yanhe River calculated by the same method are larger than those in the Dongting Lake [7]. Combined with the analysis of 4.1, it can be speculated that the change of the underlying surface might account for that runoff being more sensitive to climate change in P2 compared with P1. Therefore, climate change and human activities are not fully independent factors, which need further research. 


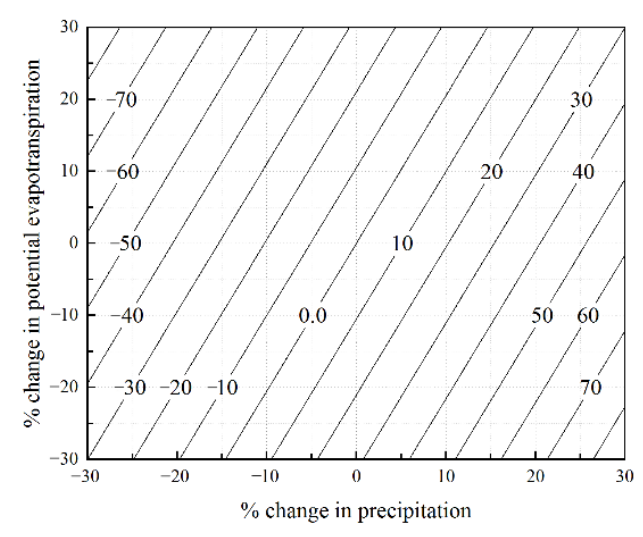

(a)

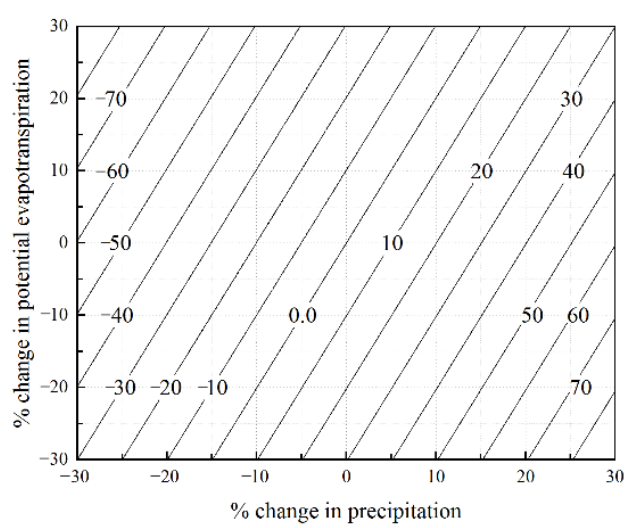

(b)

Figure 6. The sensitivity of the runoff $(Q)$ to changes in climate $\left(P, E_{0}\right):(\mathbf{a}) \%$ change in the runoff in $\mathrm{P} 1$; (b) \% change in the runoff in P2.

\section{Conclusions}

In this study, the meteorological and hydrological data from 1961 to 2019 of the Dongting Lake are analyzed; eight methods are used to decompose the effects of climate change and human activities on runoff alteration, and the factors for runoff changing are analyzed; sensitivity of the runoff to changes in climatic variables is analyzed. The key findings are summarized as follows:

(1) According to the MK test, the mutation of runoff occurred in 1984 and 2005, so the study period is divided into three periods: 1961-1983 (BP), 1984-2004 (P1), and 2005-2019 (P2). Precipitation increases in $\mathrm{P} 1$ and decreases in $\mathrm{P} 2$ compared with BP, while potential evapotranspiration decreases in $\mathrm{P} 1$ and increases in P2 compared with BP. Temperature and actual evapotranspiration have the same changing tendency, they increase with time in three periods. Runoff increases in P1 and decreases in P2.

(2) The results of eight methods indicate that climate change causes runoff increases $386 \%$ to $669 \%$ (average 518\%) while human activities make it decrease 286\% to 569\% (average $418 \%$ ) in P1. Climate change plays a prime role in altering runoff in P1. Based on the Budyko-based methods, the decline of runoff caused by human activities account for $88 \%$ to $93 \%$ (average $91 \%$ ), while the decline of runoff caused by climate change accounts for $7 \%$ to $12 \%$ in P2. Human activities are the main factors for runoff change in $\mathrm{P} 2$.

(3) For P1, a climatic factor especially precipitation is the main factor that influences the runoff. For P2, human activities such as reservoirs construction, water consumption, and land-use (land-cover) change are the main factors that influence the runoff in the Dongting Lake. The mechanisms for human activities to alter runoff and how much they each change the runoff need further research.

(4) According to the sensitivity analysis, runoff in the Dongting Lake is more sensitive to climate change in P2 compared with P1. Besides, no matter in P1 or P2, runoff is more sensitive to change in precipitation than a change in potential evapotranspiration. Combined with climate forecast, the results of sensitivity analysis can be used to estimate runoff change caused by climate change in the future.

Author Contributions: This paper was finished by collaboration among all authors. Conceptualization, Y.H. and H.T.; data curation, Y.H., H.T. and M.Y.; formal analysis, Y.H. and H.T.; funding acquisition, M.Y.; investigation, Y.H. and H.T.; methodology, Y.H.; writing for the original draft, Y.H.; writing for review and editing, M.Y., Y.H., H.T. and Y.L. All authors have read and agreed to the published version of the manuscript.

Funding: This research was funded by the National Key Research and Development Program of China, grant number [2016YFC0402303] and the National Natural Science Foundation of China, grant number [11972265].

Conflicts of Interest: The authors declare no conflict of interest. The funders had no role in the design of the study; in the collection, analyses, or interpretation of data; in the writing of the manuscript, or in the decision to publish the results. 


\section{References}

1. Huntington, T.G. Evidence for intensification of the global water cycle: Review and synthesis. J. Hydrol. 2006, 319, 83-95. [CrossRef]

2. Tomer, M.D.; Schilling, K. A simple approach to distinguish land-use and climate-change effects on watershed hydrology. J. Hydrol. 2009, 376, 24-33. [CrossRef]

3. Liu, Z.; Cuo, L.; Li, Q.J.; Liu, X.S.; Ma, X.L.; Liang, L.Q.; Ding, J. Impacts of Climate Change and Land Use/Cover Change on Streamflow in Beichuan River Basin in Qinghai Province, China. Water 2020, $12,1198$. [CrossRef]

4. Graham, L.P.; Andréasson, J.; Carlsson, B. Assessing climate change impacts on hydrology from an ensemble of regional climate models, model scales and linking methods-A case study on the Lule River basin. Clim. Chang. 2007, 81, 293-307. [CrossRef]

5. Yang, Y.H.; Weng, B.S.; Man, Z.H.; Yu, Z.L.; Zhao, J.L. Analyzing the contributions of climate change and human activities on runoff in the Northeast Tibet Plateau. J. Hydrol. Reg. Stud. 2020, 27, 100639. [CrossRef]

6. Peng, S.Z.; Liu, W.X.; Wang, W.G.; Shao, Q.X.; Jiao, X.Y.; Yu, Z.B.; Xing, W.Q.; Xu, J.Z.; Zhang, Z.X.; Luo, Y.F. Estimating the Effects of Climatic Variability and Human Activities on Streamflow in the Hutuo River Basin, China. J. Hydrol. Eng. 2013, 18, 422-430. [CrossRef]

7. Qiang, Z.; Liu, J.Y.; Singh, V.P.; Gu, X.H.; Chen, X.H. Evaluation of impacts of climate change and human activities on streamflow in the Poyang Lake basin, China. Hydrol. Process. 2016, 30, 2562-2576. [CrossRef]

8. Wang, X.X. Advances in separating effects of climate variability and human activity on stream discharge: An overview. Adv. Water Resour. 2014, 71, 209-218. [CrossRef]

9. Wu, J.W.; Miao, C.Y.; Zhang, X.M.; Yang, T.T.; Duan, Q.Y. Detecting the quantitative hydrological response to changes in climate and human activities. Sci. Total. Environ. 2017, 586, 328-337. [CrossRef]

10. Gao, P.; Mu, X.M.; Wang, F.; Li, R. Changes in streamflow and sediment discharge and the response to human activities in the middle reaches of the Yellow River. Hydrol. Earth Syst. Sci. 2011, 15, 1-10. [CrossRef]

11. Zhao, Y.F.; Zou, X.Q.; Liu, Q.; Yao, Y.L.; Li, Y.L.; Wu, X.W.; Wang, C.L.; Yu, W.W.; Wang, T. Assessing natural and anthropogenic influences on water discharge and sediment load in the Yangtze River, China. Sci. Total. Environ. 2017, 920-932. [CrossRef] [PubMed]

12. Schaake, J.C. From climate to flow. In Climate Change and U.S. Water Resources; Waggoner, P.E., Ed.; John Wiley: New York, NY, USA, 1990.

13. Sankarasubramanian, A.; Vogel, R.M.; Limbrunner, J.F. Climate elasticity of streamflow in the United States. Water Resour. Res. 2001, 37, 1771-1781. [CrossRef]

14. Arora, V.K. The use of the aridity index to assess climate change effect on annual runoff. J. Hydrol. 2002, 265, 164-177. [CrossRef]

15. Budyko, M.I. Climate and Life; Miller, D.H., Translator; Academic Press: San Diego, CA, USA, 1974.

16. Gao, G.Y.; Fu, B.J.; Wang, S.; Liang, W.; Jiang, X.H. Determining the hydrological responses to climate variability and land use/cover change in the Loess Plateau with the Budyko framework. Sci. Total. Environ. 2016, 557, 331-342. [CrossRef] [PubMed]

17. Wang, X.X.; Shang, S.Y.; Yang, W.H.; Clary, C.R.; Yang, D.W. Simulation of land use-soil interactive effects on water and sediment yields at watershed scale. Ecol. Eng. 2010, 36, 328-344. [CrossRef]

18. Ma, H.; Yang, D.W.; Tan, S.K.; Gao, B.; Hu, Q.F. Impact of climate variability and human activity on streamflow decrease in the Miyun Reservoir catchment. J. Hydrol. 2010, 389, 317-324. [CrossRef]

19. Ye, X.; Zhang, Q.; Liu, J.; Li, X.; Xu, C.Y. Distinguishing the relative impacts of climate change and human activities on variation of streamflow in the Poyang Lake catchment, China. J. Hydrol. 2013, 494, 83-95. [CrossRef]

20. Zhou, Y.Q.; Jeppesen, E.; Li, J.B.; Zhang, Y.L.; Zhang, X.P.; Li, X.C. Impacts of Three Gorges Reservoir on the sedimentation regimes in the downstream-linked two largest Chinese freshwater lakes. Sci. Rep. 2016, 6, 35396. [CrossRef]

21. Zou, Y.A.; Zhang, P.Y.; Zhang, S.Q.; Chen, X.S.; Li, F.; Deng, Z.M.; Yang, S.; Zhang, H.; Li, F.Y.; Xie, Y.H. Crucial sites and environmental variables for wintering migratory waterbird population distributions in the natural wetlands in East Dongting Lake, China. Sci. Total. Environ. 2019, 655, 147-157. [CrossRef]

22. Xie, P. Biodiversity crisis in the Yangtze River: The culprit was dams, followed by overfishing. J. Lake Sci. 2017, 29, 1279-1299. (In Chinese) 
23. Yu, Y.; Mei, X.F.; Dai, Z.J.; Gao, J.J.; Li, J.B.; Wang, J.; Lou, Y.Y. Hydromorphological processes of Dongting Lake in China between 1951 and 2014. J. Hydrol. 2018, 562, 254-266. [CrossRef]

24. Zhou, Y.Q.; Ma, J.R.; Zhang, Y.L.; Li, J.B.; Feng, L.; Zhang, Y.B.; Shi, K.; Brookes, J.D.; Jeppesen, E. Influence of the three Gorges Reservoir on the shrinkage of China's two largest freshwater lakes. Glob. Planet. Chang. 2019, 177, 45-55. [CrossRef]

25. Ou, C.M.; Li, J.B.; Zhang, Z.Q.; Li, X.C.; Yu, G.; Liao, X.H. Effects of the dispatch modes of the Three Gorges Reservoir on the water regimes in the Dongting Lake area in typical years. J. Geogr. Sci. 2012, 22, 594-608. [CrossRef]

26. Voigt, A.; Shaw, T.A. Circulation response to warming shaped by radiative changes of clouds and water vapour. Nat. Geosci. 2015, 8, 102-106. [CrossRef]

27. Yuan, Y.J.; Zhang, C.; Zeng, G.M.; Liang, J.; Guo, S.L.; Huang, L.; Wu, H.P.; Hua, S.S. Quantitative assessment of the contribution of climate variability and human activity to streamflow alteration in Dongting Lake, China. Hydrol. Process. 2016, 30, 1929-1939. [CrossRef]

28. Mao, D.H.; Feng, C.; Zhou, H.; Hu, G.W.; Li, Z.Z.; Guo, R.Z. Hunan Normal University; Province, C.H.A.W.R.S.B.O.H.; Hunan Industry University The runoff variation characteristics of Dongting Lake, China. Tecnol. Ciencias Agua 2017, 8, 77-91. [CrossRef]

29. Allen, R.G.; Pereira, L.S.; Raes, D.; Smith, M. Crop Evapotranspiration (guidelines for computing crop water requirements). FAO Irrig. Drain. Pap. 1998, 56, 205-226.

30. Lam, N.S.N. Spatial Interpolation Methods: A Review. Am. Cartogr. 1983, 10, 129-150. [CrossRef]

31. Zhao, G.J.; Tian, P.; Mu, X.M.; Jiao, J.Y.; Wang, F.; Gao, P. Quantifying the impact of climate variability and human activities on streamflow in the middle reaches of the Yellow River basin, China. J. Hydrol. 2014, 519, 387-398. [CrossRef]

32. Zhao, G.J.; Mu, X.M.; Jiao, J.Y.; Gao, P.; Sun, W.Y.; Li, E.H.; Wei, Y.H.; Huang, J.C. Assessing response of sediment load variation to climate change and human activities with six different approaches. Sci. Total. Environ. 2018, 639, 773-784. [CrossRef]

33. Searcy, J.K.; Hardison, C.H. Double-mass curves, Manual of hydrology: Part 1. General Surface-Water Techniques. Geolog. Surv. Water-Supp. Paper 1950, 31.

34. Donohue, R.J.; Roderick, M.L.; McVicar, T.R. Roots, storms and soil pores: Incorporating key ecohydrological processes into Budyko's hydrological model. J. Hydrol. 2012, 436, 35-50. [CrossRef]

35. Jiang, C.; Xiong, L.H.; Wang, D.B.; Liu, P.; Guo, S.L.; Xu, C.Y. Separating the impacts of climate change and human activities on runoff using the Budyko-type equations with time-varying parameters. J. Hydrol. 2015, 522, 326-338. [CrossRef]

36. Li, C.B.; Wang, L.M.; W, W.R.; Qi, J.G.; Y, L.S.; Zhang, Y.; Wu, L.; Cui, X.; Wang, P. An analytical approach to separate climate and human contributions to basin streamflow variability. J. Hydrol. 2018, 559, 30-42. [CrossRef]

37. Dingman, S.L. Physical Hydrology; Prentice Hall: Upper Saddle River, NJ, USA, 2002.

38. Schreiber, P. Uber die Beziehungen zwischen dem Niederschlag und der Wasserfu "hrung der Flu "ße in Mitteleuropa. Meteorol. Z. 1904, 21, 441-452.

39. Ol'dekop, E.M. On Evaporation from the Surface of River Basins: Transactions on Meteorological Observations. Lur-evskogo; Report. Univ. of Tartu: Tartu, Estonia, 1911. (In Russian)

40. Pike, J. The estimation of annual run-off from meteorological data in a tropical climate. J. Hydrol. 1964, 2,116-123. [CrossRef]

41. Turc, L. Le bilan d'eau des sols. Relation entre la precipitation, l'evaporation et l'e'coulement. Ann. Agron. 1954, 5, 491-569.

42. Budyko, M.I. Evaporation Under Natural Conditions; Isr. Program for Sci: Jerusalem, Israel, 1948.

43. Fu, B.P. The calculation of the evaporation from land surface. Chin. J. Atmos. Sci. 1981, 5, $23-31$.

44. Zhang, L.Y.S.; Dawes, W.R.; Walker, G.R. Response of mean annual evapotranspiration to vegetation changes at catchment scale. Water Resour. Res. 2001, 37, 701-708. [CrossRef]

45. Mann, H.B. Nonparametric Tests Against Trend. Econometrica 1945, 13, 245-259. [CrossRef]

46. Kendall, M.G. Rank Correlation Methods; Griffin: Irvine, CA, USA, 1948.

47. WMO Statement on the State of the Global Climate In 2019; WMO: Geneva, Switzerland, 2020.

48. Wang, R.N.; Peng, W.Q.; Liu, X.B.; Jiang, C.L.; Wu, W.Q.; Chen, X.K. Characteristics of Runo Variations and Attribution Analysis in the Poyang Lake Basin over the Past 55 Years. Sustainability 2020, 12, 944. [CrossRef] 
49. Hunan Water Resources Bulletin. 2001-2018. Available online: http://slt.hunan.gov.cn/xxgk/tjgb (accessed on 8 September 2020).

50. Long, Q.B.; Wang, S.B. Study on statistical caliber classification and sampling survey method of total water use in Hunan Province. Hunan Hydro Power. 2019, 220,31-34. (In Chinese)

51. Deng, F.; Wang, X.L.; Cai, X.B.; Li, E.H.; Jiang, L.Z.; Li, H.; Yan, R.R. Analysis of the relationship between inundation frequency and wetland vegetation in Dongting Lake using remote sensing data. Ecohydrology 2013, 7, 717-726. [CrossRef]

(C) 2020 by the authors. Licensee MDPI, Basel, Switzerland. This article is an open access article distributed under the terms and conditions of the Creative Commons Attribution (CC BY) license (http://creativecommons.org/licenses/by/4.0/). 